\title{
Application of Neutralizing Antibodies against NI-35/250 Myelin-Associated Neurite Growth Inhibitory Proteins to the Adult Rat Cerebellum Induces Sprouting of Uninjured Purkinje Cell Axons
}

\author{
Annalisa Buffo, ${ }^{1}$ Marta Zagrebelsky, ${ }^{1}$ Andrea B. Huber, ${ }^{2}$ Arne Skerra, ${ }^{3}$ Martin E. Schwab, ${ }^{2}$ Piergiorgio Strata, \\ and Ferdinando Rossi ${ }^{1}$ \\ ${ }^{1}$ Department of Neuroscience and "Rita Levi Montalcini Center for Brain Repair," University of Turin, I-10125 Turin, Italy, \\ ${ }^{2}$ Brain Research Institute, University of Zurich, and Federal Institute of Technology, CH-8057 Zurich, Switzerland, and \\ ${ }^{3}$ Lehrstuhl für Biologische Chemie, Technische Universität München, D-85350 München, Germany
}

The myelin-associated proteins NI-35/250 exert a powerful inhibition on axon regeneration, but their function exerted on intact neurons is still unclear. In the adult CNS these proteins are thought to regulate axon growth processes to confine plasticity within restricted regions and to prevent the formation of aberrant connections. We have recently shown that application of neutralizing IN-1 antibody Fab fragment against NI-35/ 250 proteins to the adult cerebellum induces the expression of injury/growth-associated markers in intact Purkinje cells. Here, we asked whether these cellular modifications are accompanied by growth phenomena of Purkinje neurites. A single intraparenchymal application of $\mathrm{IN}-1$ Fab fragment to the adult cerebellum induces a profuse sprouting of Purkinje axons along their intracortical course. The newly formed processes spread to cover most of the granular layer depth. A significant axon outgrowth is evident $2 \mathrm{~d}$ after injection; it tends to increase at 5 and $7 \mathrm{~d}$, but it is almost completely reversed after 1 month. No axonal modifications occur in control Fab-treated cerebella. The IN-1 Fab fragment-induced cellular changes and axon remodeling are essentially reproduced by applying affinitypurified antibody 472 raised against a peptide sequence of the recombinant protein $\mathrm{NI}-220$, thus confirming the specificity of the applied treatments on these myelin-associated molecules. Functional neutralization of NI-35/250 proteins induces outgrowth from uninjured Purkinje neurites in the adult cerebellum. Together with previous observations, this suggests that these molecules regulate axonal plasticity to maintain the proper targeting of terminal arbors within specific gray matter regions.

Key words: sprouting; myelin-associated neurite growth inhibitors; axon growth-associated proteins; axon regeneration; intrinsic determinants; cerebellum
The progressive decline of the neuronal potential for axon growth and plasticity that occurs at the end of CNS development has been attributed to intrinsic changes of the maturing nerve cells concomitant to modifications of their microenvironment (Skene, 1989, 1992; Schwab et al., 1993; Chen et al., 1995; Holm and Isacson, 1999). The restriction of neurite growth capabilities has been particularly related to the maturation of white matter tracts, and several myelin-associated molecules have been described that exert a strong inhibitory action on axon elongation and regeneration (Caroni and Schwab, 1988; Schwab et al., 1993; McKerracher et al., 1994; Mukhopadhyay et al., 1994). The NI-35/250 proteins are expressed by oligodendrocytes shortly before the onset of central axon myelination (Caroni and Schwab, 1989), and their distribution is inversely related to that of the growthassociated protein GAP-43 (Kapfhammer and Schwab, 1994a).

\footnotetext{
Received Sept. 14, 1999; revised Dec. 9, 1999; accepted Jan. 3, 2000.

This work was supported by grants from Ministero dell'Università e della Ricerca Scientifica e Tecnologica, Consiglio Nazionale delle Ricerche, Italian Telethon (Grant 1130), European Community Biotechnology Programme (ERBBIO4-CT960774), and International Foundation for Paraplegia. We are indebted to Dr. Michaela Thallmair for her comments on this manuscript. We thank Luisella Milano for technical help and Graziella Milano for secretarial assistance.

A.B. and M.Z. contributed equally to this paper.

Correspondence should be addressed to Ferdinando Rossi, Department of Neuroscience, University of Turin, Corso Raffaello 30, I-10125 Turin, Italy. E-mail: rossi@medfarm.unito.it.

Copyright (C) 2000 Society for Neuroscience $\quad 0270-6474 / 00 / 202275-12 \$ 15.00 / 0$
}

Oligodendrocyte deletion during development results in the ectopic localization of GAP-43 in white matter (Kapfhammer and Schwab, 1994b) accompanied by aberrant growth of corticospinal fibers out of their natural pathway (Schwab and Schnell, 1991) and sprouting of optic nerve axons (Colello and Schwab, 1994). In addition, neutralization of these proteins in the maturing brain prolongs permissive periods for compensatory sprouting in the spinal cord and brainstem (Schwegler et al., 1995; Vanek et al., 1998) and for activity-dependent plasticity in the visual system (Müller et al., 1994). Therefore, it has been suggested that NI$35 / 250$ proteins exert a boundary function for developing projection pathways to prevent aberrant growth and the establishment of abnormal connections. In the adult, they would participate in the maintenance of connection specificity by restricting plasticity to terminal axon territories and preventing unwanted sprouting along white matter tracts (Schwab et al., 1993; Schwab and Bartholdi, 1996). In line with this view, the application of neutralizing IN-1 antibodies against the NI-35/250 proteins enhances compensatory sprouting of spared corticospinal axons after unilateral pyramidotomy (Thallmair et al., 1998; Z'Graggen et al., 1998). Nevertheless, direct evidence that NI-35/250 protein neutralization can induce the growth of intact axons in the adult uninjured brain is still lacking.

We have recently investigated the role played by these proteins in regulating the response to injury of adult Purkinje cells, which 
are most peculiar for their poor intrinsic regenerative potential (Rossi et al., 1995a; Bravin et al., 1997; Dusart et al., 1997). A single injection of the IN-1 Fab fragment into the intact cerebellum of adult rats induces a transient but strong upregulation of several injury/growth-associated markers, indicating that these myelin-associated molecules may exert a constitutive retrograde inhibition on the expression of injury/growth-associated genes in adult central neurons (Zagrebelsky et al., 1998). To assess whether these cellular changes are accompanied by neurite growth phenomena, we have now performed an extensive qualitative and quantitative morphometric analysis of Purkinje axons after the application of IN-1 Fab fragment to the intact cerebellum. Our results strongly indicate that NI-35/250 proteins exert a constitutive inhibitory control on adult uninjured neurons to prevent unwanted and potentially aberrant growth processes.

A preliminary report of this work has been published previously (Buffo et al., 1999).

\section{MATERIALS AND METHODS}

Animals and surgical procedures. All of the experiments were performed on adult Wistar rats (Charles River, Calco, Italy) deeply anesthetized by means of intraperitoneal administration of a mixture of ketamine (100 $\mathrm{mg} / \mathrm{kg}$, Ketalar; Bayer, Leverkusen, Germany) and xylazine $(5 \mathrm{mg} / \mathrm{kg}$, Rompun; Bayer). The experimental plan was designed according to the Italian law for care and use of experimental animals (DL116/92) and approved by the Italian Ministry of Health. Some of the animals examined for this study belong to an experimental set described in a previous paper (Zagrebelsky et al., 1998).

Fab fragment or antibody injections were performed as previously described (Zagrebelsky et al., 1998). The animals were placed in a stereotaxic apparatus, and the dorsal cerebellar vermis was exposed by drilling a small hole on the posterosuperior aspect of the occipital bone. The meninges were left intact except for the small hole produced by the injection pipette penetration. In 16 rats a recombinant Fab fragment of the IN-1 antibody (produced in Escherichia coli), which neutralizes myelin-associated neurite growth inhibitory proteins (Caroni and Schwab, 1988; Bandtlow et al., 1996), was injected into the cerebellar parenchyma. Three $1 \mu \mathrm{l}$ injections of Fab fragments in saline solution $(5 \mathrm{mg} / \mathrm{ml})$ were performed $0.5-1 \mathrm{~mm}$ deep along the cerebellar midline into the dorsal vermis (lobules V-VII). The injections were made by means of a glass micropipette connected to a PV800 Pneumatic Picopump (WPI, New Haven, CT). The frequency and duration of pressure pulses were adjusted to inject $1 \mu \mathrm{l}$ of the solution during a period of $\sim 10 \mathrm{~min}$. The pipette was left in situ for 5 additional minutes to avoid an excessive leakage of the injected solution. As a control, an affinitypurified $\mathrm{F}\left(\mathrm{ab}^{\prime}\right)_{2}$ fragment of a mouse anti-human IgG (Jackson ImmunoResearch Laboratories, West Grove, PA) was applied to another set of 16 rats using the same procedure. Survival times for these two experimental sets were 2, 5, 7 and $30 \mathrm{~d}$ (four animals for each time point). An additional set of animals $(n=8)$ received injections of the rabbit antibody 472 raised against a peptide of the NI-220 protein (Huber et al., 1998), according to the same procedure. The antibody was purified on an affinity column with the corresponding peptide and was used at a protein concentration of $0.5 \mathrm{mg} / \mathrm{ml}$. Control experiments were performed in another eight rats by injecting preimmune serum of antibody 472, affinity-purified over the same peptide column, to which normal rabbit $\mathrm{IgG}$ was added to reach the same concentration as antibody $472(0.5$ $\mathrm{mg} / \mathrm{ml}$ ). In these experiments, survival times were 2 and $5 \mathrm{~d}$ (four rats for each time point). Finally, four intact animals were examined as untreated controls.

Histological procedures. At different survival times after surgery, under deep general anesthesia (as above), the rats were transcardially perfused with 11 of $4 \%$ paraformaldehyde in $0.12 \mathrm{M}$ phosphate buffer, $\mathrm{pH}$ 7.2-7.4. The brains were immediately dissected, stored overnight in the same fixative at $4^{\circ} \mathrm{C}$, and finally transferred in $30 \%$ sucrose in $0.12 \mathrm{M}$ phosphate buffer at $4^{\circ} \mathrm{C}$ until they sank. The cerebella were cut using a freezing microtome in several series of $30-\mu \mathrm{m}$-thick sagittal sections. One series was processed for NADPH diaphorase histochemistry. These sections were incubated for $3-4 \mathrm{hr}$ in darkness at $37^{\circ} \mathrm{C}$ in a solution composed of $\beta$-NADPH (1 mg/ml, Sigma, St. Louis, MO) and nitroblue tetrazolium $(0.2 \mathrm{mg} / \mathrm{ml}$, Sigma) in $0.12 \mathrm{M}$ phosphate buffer with $0.25 \%$ Triton X-100.
In some cases (two animals per treated and control sets at 2 and $5 \mathrm{~d}$ survival), microglia were stained by incubating one section series with biotinylated Griffonia simplicifolia isolectin B4 [1:100 in phosphate buffer with $0.25 \%$ Triton X-100; Sigma (Rossi et al., 1994a)] overnight at $4^{\circ} \mathrm{C}$. The sections were subsequently incubated for $30 \mathrm{~min}$ in the avidinbiotin-peroxidase complex (Vectastain, ABC Elite kit, Vector, Burlingame, CA) and revealed using the $3,3^{\prime}$ diaminobenzidine $(0.03 \%$ in Tris $\mathrm{HCl}$ ) as a chromogen.

All of the other series were first incubated in $0.3 \% \mathrm{H}_{2} \mathrm{O}_{2}$ in PBS to quench endogenous peroxidase. Then, they were incubated for $30 \mathrm{~min}$ at room temperature and overnight at $4{ }^{\circ} \mathrm{C}$ with different primary antibodies: anti-calbindin D-28K (monoclonal, 1:5000, Swant, Bellinzona, Switzerland), to visualize Purkinje cells; anti-c-Jun (polyclonal, 1:1000, Santa Cruz Biotechnology, Santa Cruz, CA); and anti-CD11b/c (monoclonal OX-42, 1:2000, Cedarlane Laboratories, Hornby, Ontario) to stain microglia. All of the antibodies were diluted in PBS with $0.25 \%$ Triton X-100 added with either normal horse serum or normal goat serum depending on the species of the second antibody. Immunohistochemical staining was performed according to the avidin-biotin-peroxidase method (Vectastain, ABC Elite kit, Vector) and revealed using the 3,3' diaminobenzidine $(0.03 \%$ in Tris $\mathrm{HCl})$ as a chromogen. The reacted sections were mounted on chrome-alum gelatinized slides, air-dried, dehydrated, and coverslipped.

Quantitative analysis. Quantification of reactive Purkinje cells in the different experiments was made by estimating the neurons labeled by c-Jun antibodies as previously described (Zagrebelsky et al., 1998). For each animal, three immunolabeled sections were chosen. Only vermal sections close to the cerebellar midline that contained the injection sites were considered. The outline of the selected sections was reproduced using the Neurolucida software (MicroBrightField, Colchester, VT) connected to an E-800 Nikon microscope, and the position of every singlelabeled cell was carefully marked. The number of labeled cells present in the three reproduced sections was averaged to calculate values for every individual animal, which were used for statistical analysis carried out by Student's $t$ test.

To perform a morphometric analysis of Purkinje axons in the different experimental conditions for each animal, three anti-calbindinimmunolabeled sections, contiguous to those examined for c-Jun, were chosen. The purpose of this analysis was to quantify the plasticity of Purkinje axons induced by IN-1 Fab fragment or antibody 472 application and to assess whether such structural changes were associated with the expression of the above-mentioned cellular markers. Although immunolabeling of 472 and control antisera-treated cerebellar sections with anti-IgG antibodies revealed some faint staining in the vermal lobules around the injection sites at 2 and $5 \mathrm{~d}$, the actual diff usion of injected Fab fragments and antibodies in the cerebellar parenchyma could not be reliably determined. In addition, the position of the injection sites slightly varied among the experimental individuals. As a consequence, to perform standard reproducible measurements on all the animals, each sampled cerebellar section was divided into three areas, depicted in Figures 2 and 5, according to the following criteria. (1) Dorsal vermis lobules V, VIa,b,c, and VII (dark gray in Fig. 2, red in Fig. 5), which contained all the injection sites and the vast majority of reactive Purkinje cells in IN-1 Fab fragment or antibody 472-treated animals (Zagrebelsky et al., 1998), were considered as cortical areas affected by antibody applications. (2) Ventral vermis lobules I and II and the dorsal portion of lobule IX (light gray in Fig. 2, green in Fig. 5), which were distant from the injection sites and contained very rarely reactive Purkinje cells, were examined as an internal control. (3) Finally, the intermediate region, e.g., lobules III and VIII, was excluded from the analysis, and so were lobules X and IX (ventral portion) because of the peculiar pattern of thereby located Purkinje axons (see Results).

Morphometric measurements were made on $200 \times 250 \mu \mathrm{m}$ areas of the granular layer that were chosen by superimposing a grid of this size on the section. The selected areas had to encompass most of the granular layer depth and to contain only minimal portions of Purkinje cell layer or axial white matter (sometimes the position of the grid had to be slightly adjusted to fit these criteria). In each of the selected sections we sampled one area from the dorsal cortical lobules and one from the ventral cortical lobules. In addition, to sample from the different parts of these two cortical regions, areas from different lobules were selected in the three sections belonging to each individual animal, typically one area in each of lobules V, VI, and VII and one in lobules I, II, and IX. Thus, for each animal we sampled three affected and three control areas belonging to different lobules. All of the anti-calbindin-immunolabeled Purkinje axon 
segments contained within the selected areas were reproduced using the Neurolucida software (MicroBrightField) connected to an E-800 Nikon microscope with $20 \times$ objective, corresponding to $750 \times$ magnification on the computer screen. Each labeled axon segment or branch was reproduced as a single profile. From these reproductions the software calculated the number of axon profiles, their individual length, and the total length of all the reproduced segments, the mean profile length (total length/number of profiles), and the number of times that the axons crossed a $25 \times 25 \mu \mathrm{m}$ grid superimposed on the selected area. Data calculated from the different areas in the three sections sampled from each cerebellum were averaged to obtain values for every individual animal. Statistical analysis was performed on the latter values $(n=4$ for all groups at all time points) by Student's $t$ test and paired $t$ test.

\section{RESULTS}

\section{Morphology of Purkinje cell axons in the intact cerebellum}

To obtain a functional blockade of the NI-35/250 proteins in the adult cerebellum, IN-1 Fab fragment injections were placed along the midline $0.5-1 \mathrm{~mm}$ deep from the vermal surface (Zagrebelsky et al., 1998). We focused our analysis on the first segment of the Purkinje axon running through the cerebellar cortex and along the folium axial white matter and excluded more distal portions of the axons as well as terminal arbors in the deep cerebellar nuclei, which were remote from the injected region. It is well established that both the intracortical segment of the neurite and the recurrent collateral branches are myelinated (Ramón y Cajal, 1911; Palay and Chan-Palay, 1974).

Purkinje axon morphology, as observed in calbindinimmunolabeled cerebellar sections from unmanipulated animals, was consistent with previous reports (Ramón y Cajal, 1911; Eccles et al., 1967; Chan-Palay, 1971; Mugnaini, 1972; Crepel et al., 1980; Bishop, 1982; De Camilli et al., 1984; Dusart and Sotelo, 1994). The main stem of the Purkinje neurite emerges from the basal perikaryon pole and runs straight across the granular layer toward the folium axial white matter (Fig. $1 A, B$ ). Along its way through the granular layer the axon emits one or two thinner collateral ramifications that ascend toward the Purkinje cell layer (Fig. 1B). Such recurrent processes ramify further along the parasagittal plane to terminate in a few beaded chains forming the infraganglionic and supraganglionic plexus (Ramón y Cajal, 1911) in the vicinity of the Purkinje cell somata. As depicted in Figure $1 A, B$, this ordered arrangement leads to a very regular pattern of smooth axon profiles radiating across the granular layer with a thin infraganglionic terminal plexus, strictly confined in the uppermost portion of this layer. In contrast, the supraganglionic plexus, which is scarcely developed in the rat, is almost completely obscured by the intense immunostaining of Purkinje dendrites.

Such a regular arrangement of the Purkinje axons can be recognized along the entire extent of the vermal cortex, except for lobule $\mathrm{X}$ and the ventral portion of lobule IX (Fig. 1C). Here, Purkinje axons form a very thick terminal network covering the whole depth of the granular layer. Such a peculiar feature of Purkinje axons in the caudal vermis has been surprisingly overlooked by previous investigators, although it likely accounts for the "recurrent plexus in the granular layer" observed by ChanPalay (1971) on Golgi-stained Purkinje cells from lobule IX. Because of this peculiar arrangement of Purkinje axons, lobules $\mathrm{X}$ and the ventral portion of lobule IX were not included in our analysis.
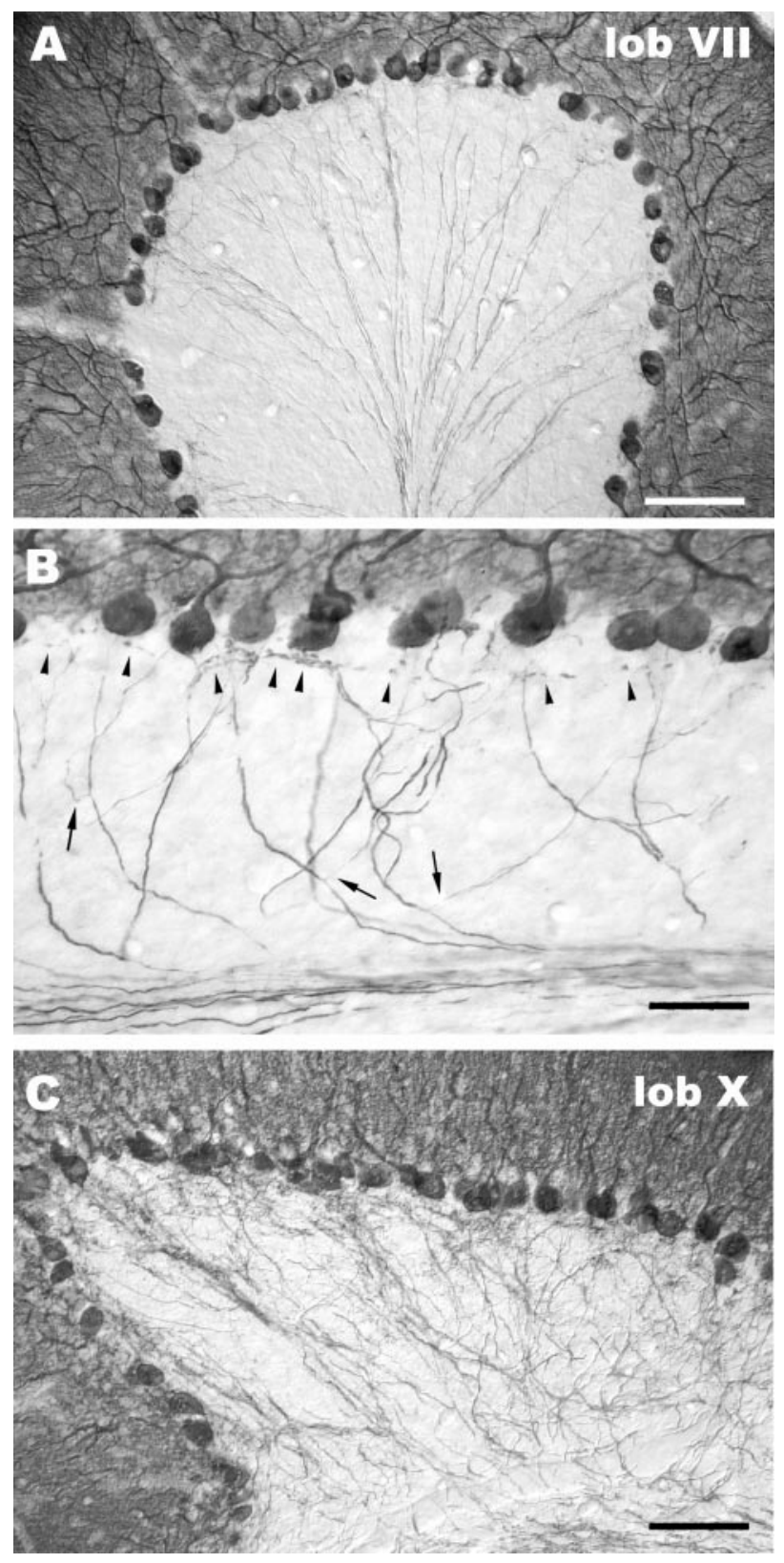

Figure 1. Morphology of Purkinje axons in the intact cerebellum. $A$ shows the typical pattern of calbindin-immunostained Purkinje axons, originating from the basal perikaryal pole and converging toward the axial white matter of the folium. At a higher magnification $(B)$, the thinner recurrent collateral branches (arrows), which ascend through the granular layer to end in the infraganglionic plexus (arrowheads), can be disclosed. This pattern is consistently observed over the whole cerebellar cortex except for lobules IX (ventral portion) and $\mathrm{X}(C)$. Here, the recurrent Purkinje axon branches form a thick terminal plexus covering the whole granule cell layer. Scale bars: $A, C, 100 \mu \mathrm{m} ; B, 50 \mu \mathrm{m}$.

\section{Structural plasticity of uninjured Purkinje axons after the application of IN-1 Fab fragment}

As reported previously (Zagrebelsky et al., 1998), a single injection of IN-1 Fab fragment, but not of a control Fab fragment, into the normal adult cerebellum induces a strong upregulation of c-Jun and JunD as well as NADPH diaphorase in numerous Purkinje cells. The changes are already evident $2 \mathrm{~d}$ after IN-1 Fab fragment application and gradually decline after 1 week. In addition, because of the position of the injection sites, the effect is 

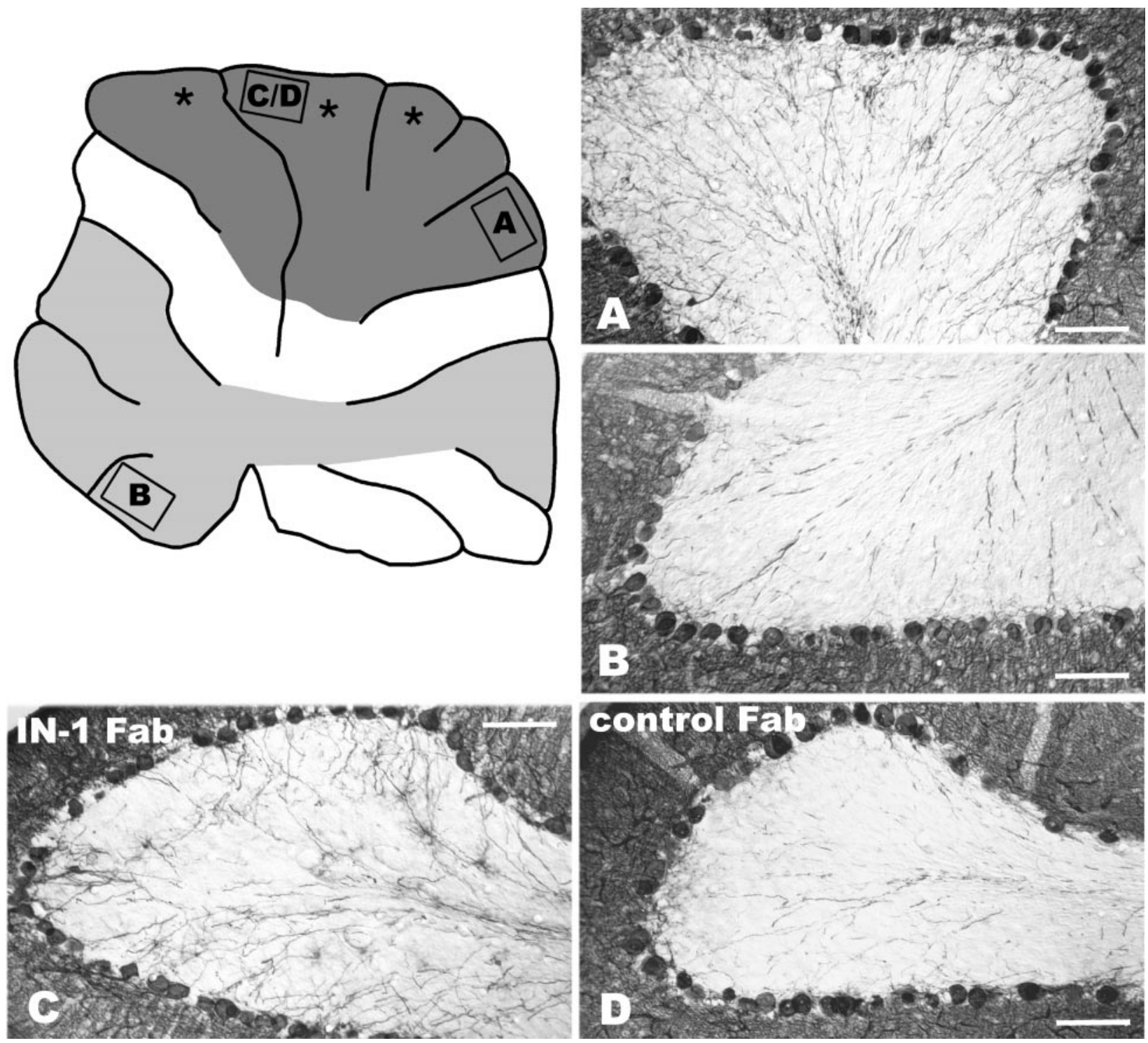

Figure 2. Structural features of the intracortical Purkinje axons in Fab fragment-treated cerebella. The diagram shows a sagittal section of the cerebellar vermis; the dark gray area indicates the dorsal vermal lobules that were affected by the injections (asterisks indicate the approximate positions of the injection sites), whereas the light gray area defines the ventral vermal lobules, examined as an internal control (see Materials and Methods and Results). The rectangles indicate the approximate position of the images shown in the relevant micrographs. $A$ and $B$ display a portion of lobules VII and I, respectively, taken from the same cerebellar section of a rat treated with the IN-1 Fab fragment at $7 \mathrm{~d}$ survival time. In $A$, the granular layer is covered by a huge number of thin axon profiles running in all directions, among which the thicker and straight-running Purkinje stem axons can be disclosed. In contrast, only the stem axons can be seen in the granular layer in $B$, and the few terminal branches are restricted to the vicinity of Purkinje cell somata. $C$ and $D$ show the tip of lobule VIa from two different cerebella $5 \mathrm{~d}$ after IN-1 or control Fab injection, respectively. Note the numerous Purkinje axon branches in the granular layer in $C$, which are not present in the same area of the control Fab-treated cerebellum $(D)$. Scale bars, $100 \mu \mathrm{m}$.

restricted to several lobules of the dorsal vermis, whereas Purkinje cells from the ventral cerebellum are unaffected. To elucidate whether these cellular modifications are associated with Purkinje axon changes, we evaluated calbindin-immunostained sections of the cerebellar vermis from such animals. The sections were subdivided into two regions (Fig. 2): (1) vermal lobules V, VIa,b,c, and VII, in which most of the reactive Purkinje cells were found, and (2) ventral lobules I, II, III, and IX (dorsal portion), where almost no reactive Purkinje cells were observed, which served as an internal control. All other regions, i.e., lobules IV, VIII, IX (ventral), and X, were excluded from the analysis.

Purkinje cells from the ventral lobules of cerebella that received an IN-1 Fab fragment injection (Fig. 2B), as well as those from the whole cortex treated with the control Fab fragment (Figs. 2D, 3A), displayed morphological features similar to those described for intact animals (see above). Only a few cells located in the close vicinity of the control Fab fragment injection site showed the typical neurite modifications of axotomized Purkinje cells (Ramón y Cajal, 1928; Dusart and Sotelo, 1994), e.g., the presence of torpedoes along the initial portion of the axon and the hypertrophy of recurrent collateral branches with arciform axons.

The picture was strikingly different in the dorsal vermal lobules treated with IN-1 Fab fragment, in which reactive Purkinje cells were localized (Zagrebelsky et al., 1998). Except for a few neurons, almost exclusively found in the vicinity of the pipette track, no Purkinje axon modifications characteristic of axotomy 


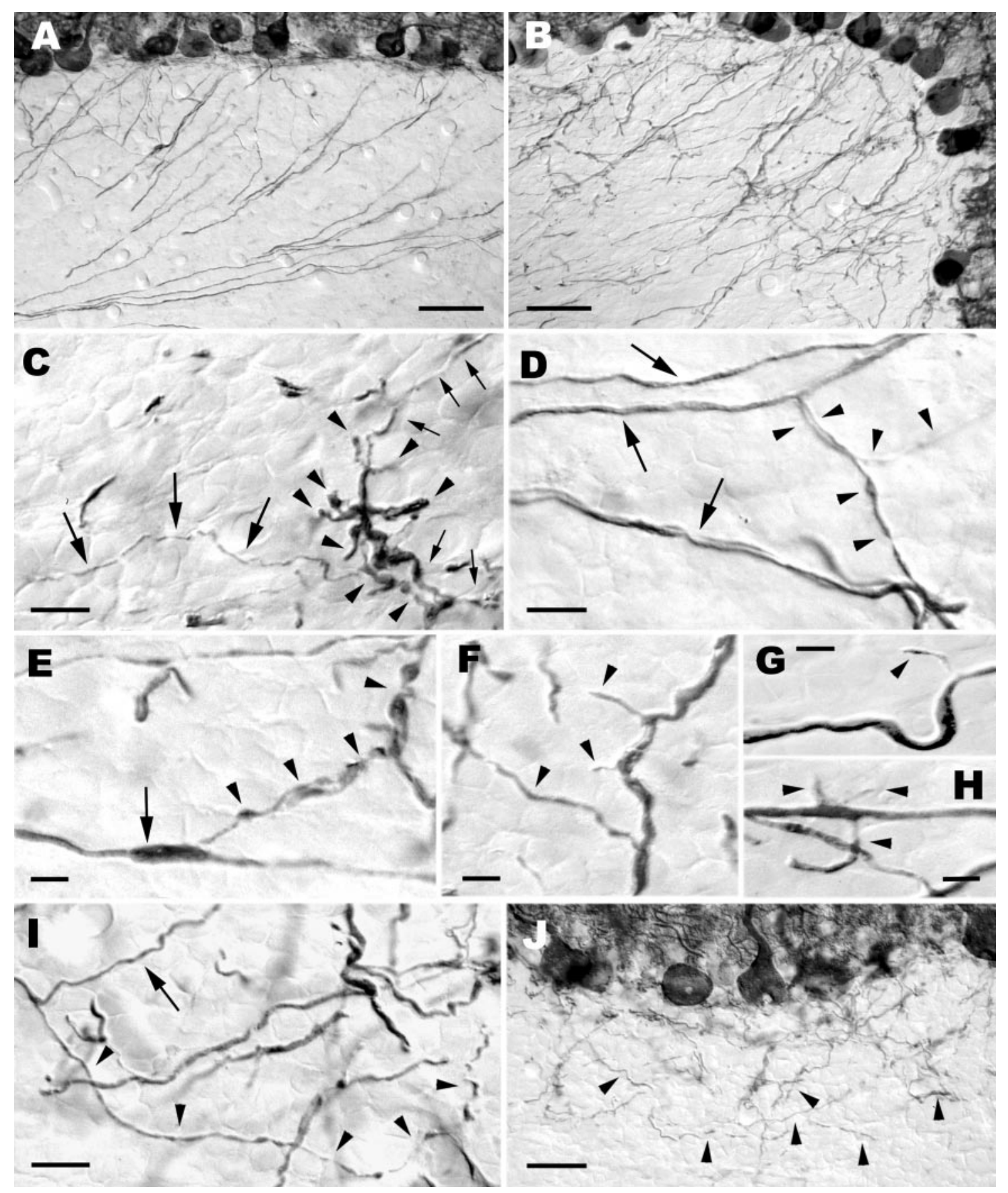

Figure 3. Morphology of Purkinje axon sprouts in IN-1 Fab fragment-treated cerebella. $A$ and $B$ show a control and an IN-1 Fab fragment-treated cerebellum, respectively. The newly formed sprouts $(B)$ form a rather dense network of randomly oriented processes with some varicose branches, among which the Purkinje stem axons can be recognized because of their straight course and thicker caliber. The Purkinje axon in $C$ (small arrows) is characterized by a thickened segment from which several short sprouts (arrowheads), bearing one or a few varicosities, and another long slender process (large arrows) originate. Arrows in $D$ point to Purkinje stem axons coursing through the granular layer; two thin branches (arrowheads) emerge at the same site along one of such axons and take divergent routes. A thin varicose chain (E, arrowheads) buds from a thickened segment of a Purkinje axon stem (arrow). Another Purkinje axon stem $(F)$ emits three processes (arrowheads) along its way; the course of the longest of such branches suggests that it may be a recurrent collateral. Arrowheads in $G$ and $H$ point to short stubby sprouts emitted by thick Purkinje axon stems in the deepest portions of the granular layer. The Purkinje axon in I (arrow) gives rise to a long branch (arrowheads) bearing several varicosities localized in its distalmost segment. $J$ shows an area from the dorsal cerebellum $30 \mathrm{~d}$ after IN-1 Fab fragment injection. Most of the sprouts in the granular layer have disappeared, although some scattered processes with a random course (arrowheads) still persist. Survival times were $2 \mathrm{~d}$ in $C, G$, and $H, 5 \mathrm{~d}$ in $I, 7 \mathrm{~d}$ in $A, B$, and $D-F$, and $30 \mathrm{~d}$ in $J$. Scale bars: $A, B, 50 \mu \mathrm{m} ; J, 30 \mu \mathrm{m} ; C, D, I, 10 \mu \mathrm{m} ; E-H, 5 \mu \mathrm{m}$.

(Ramón y Cajal, 1928; Dusart and Sotelo, 1994) or other degenerative phenomena (Rossi et al., 1994b, 1995b) were observed. On the contrary, in wide areas of the dorsal vermal cortex, the granular layer displayed a clear-cut increase of calbindin- immunostained profiles running in all directions, among which the stem axons heading toward the white matter could be recognized for their typical course and slightly thicker caliber (Figs. $2 A, C, 3 B$ ). The newly formed processes could be divided into 

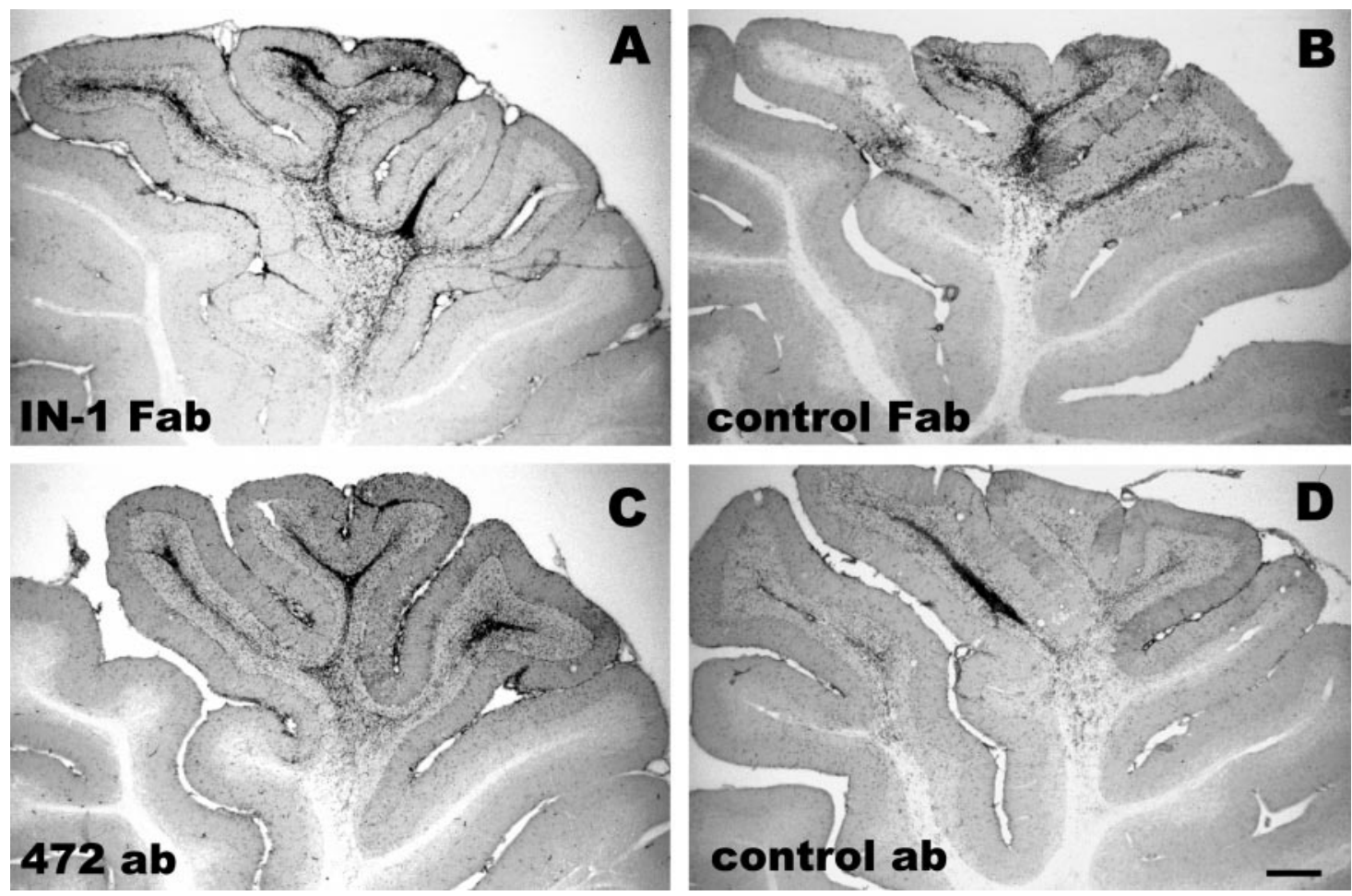

Figure 4. Activation of microglia by Fab fragment or antibody injections to the cerebellum. The micrographs show microglia stained by G. simplicifolia isolectin B4 in cerebellar sections $2 \mathrm{~d}$ after injections of IN-1 Fab fragment $(A)$, control Fab fragment $(B)$, antibody $472(C)$, and control antibody $(D)$. All of the injections induced a similar recruitment of ameboid elements in the vicinity of injection sites and increased density of branched cells in the adjacent cortex. Scale bar, $500 \mu \mathrm{m}$.

three main categories: (1) short stubby sprouts, a few tens of micrometers long, that sometimes ended with a round-shaped bouton (Fig. 3C, $F-H$ ); (2) long thin processes, bearing rare varicosities, which ran for several hundred micrometers across the granular layer without clear orientation (Fig. 3C, D); and (3) a minority of thin varicose branches, several tens of micrometers long, similar to the terminal ramifications of the infraganglionic plexus (Fig. 3E,I).

Most of these newly formed processes appeared as isolated profiles whose site of origin from the Purkinje axon could not be determined. However, analysis at high magnification in many instances revealed that they bud from the main Purkinje axon (Fig. $3 C-I$ ), and in some cases several stubby sprouts and long processes emanated from restricted axon segments (Fig. $3 C, D, H$ ), which may appear thickened and twirled (Fig. 3C). Although a few of such processes might represent recurrent branches (Fig. $3 F$ ), most of them could be identified as newly formed processes because of their characteristic morphology, high frequency, and random orientation. On the other hand, it was difficult to identify new processes emerging from recurrent branches, because the latter have a thin caliber and ramify along their course. However, the high frequency of branching points that could be disclosed within the dense network of randomly oriented thin profiles in the granular layer (Fig. 3B) strongly indicates that sprouting also occurred along recurrent Purkinje axon collaterals.

The newly formed branches were especially numerous in the upper two-thirds of the granular layer, but they were clearly detectable also in the deeper portions. By contrast, in the folium axial white matter, Purkinje axons displayed the typical arrange- ment in parallel bundles, and we could not disclose any clear morphological modification. The structural changes were present in wide areas of the dorsal vermal cortex, although their extent and intensity were somewhat variable. They were already quite evident $2 \mathrm{~d}$ after injection of the IN-1 antibody Fab fragment, and they appeared to be more pronounced at 5 and $7 \mathrm{~d}$.

To assess whether these axonal changes were reversible, we analyzed an additional set of animals killed $30 \mathrm{~d}$ after Fab fragment application. The cerebella injected with IN-1 Fab fragment still displayed sparse Purkinje cells reactive for c-Jun immunolabeling or NADPH diaphorase histochemistry scattered along the affected folia. In contrast, only one or two reactive neurons per section were found in the cerebella treated with the control Fab fragment, and they were always localized in the close vicinity of the injection track. The axon pattern in the granular layer of both control and IN-1-treated cerebella was similar, and it was not overtly different from that observed in the intact animals. However, in the IN-1-treated cerebella we could observe restricted areas, which still displayed some scattered axon profiles with a twining course and random orientation (Fig. $3 J$ ). On the whole, however, qualitative observation at this long survival time showed that most of the axon changes observed at earlier time points had reversed.

In these experiments the effects of IN-1 Fab fragment produced in E. coli were compared with those induced by a control Fab fragment from a monoclonal antibody (see Materials and Methods). To rule out the possibility that Purkinje axon morphology might be affected by inflammation produced by bacterial impurities remaining after preparation of the IN-1 Fab fragment, we examined microglia activation in the treated cerebella by 

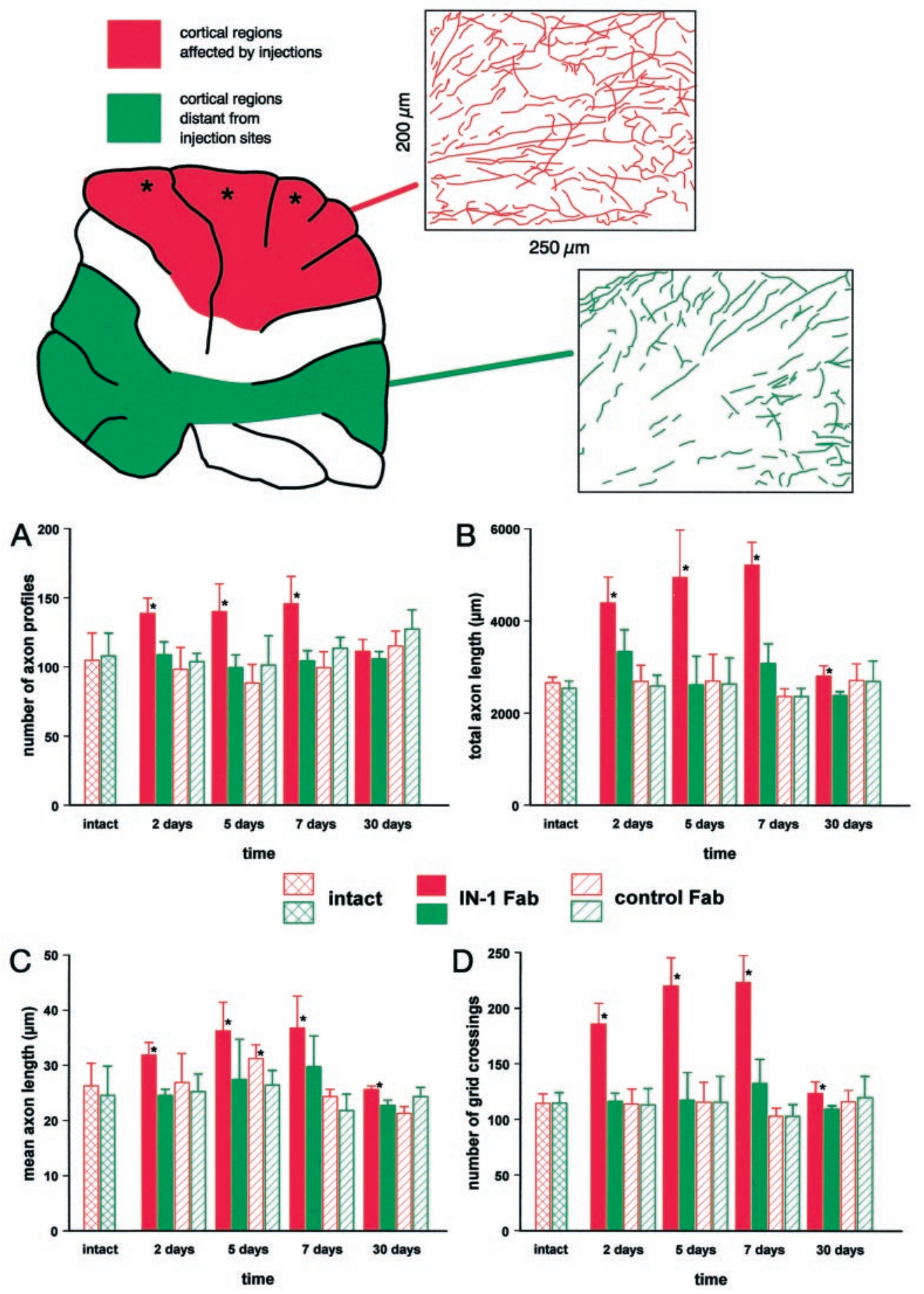

Figure 5. Quantitative analysis of IN-1 Fab fragment-induced Purkinje axon sprouting. The diagram illustrates a sagittal section of the vermis; the red labeling indicates the dorsal vermal lobules affected by the injections (asterisks indicate the approximate positions of the injections sites), whereas the green labeling defines the ventral vermal lobules, examined as an internal control (see Results). In addition, two representative $200 \times 250 \mu \mathrm{m}$ areas taken from dorsal and ventral cortex, respectively, are displayed in which all Purkinje axon profiles have been reproduced and measured. $A-D$ show the results of the morphometric analysis performed on such sampled areas (for details, see Materials and Methods and Results). No differences exist between the values obtained from dorsal (red labeling of columns) and ventral ( green labeling of columns) lobules in intact (cross-hatched columns) and control Fab-treated animals (hatched columns). In contrast, after injection of IN-1 Fab fragment (solid columns), all of the values from the dorsal lobules are consistently higher than those from the ventral lobules at 2, 5, and $7 \mathrm{~d}$, but they return to control levels at $30 \mathrm{~d}$. Asterisks indicate values that are significantly different from the relevant internal control (for details, see Results).

G. simplicifolia isolectin B4 staining or anti-CD11a/b immunolabeling, which yields similar results. In both IN-1 (Fig. 4A) and control Fab fragment animals (Fig. 4B) (two animals for each group at each time point, 2 and $5 \mathrm{~d}$ ), we did observe a similar recruitment of ameboid elements in the vicinity of the injection sites and an increased density of branched cells in the adjacent cortical layers. The intensity of such a reaction was variable among the animals, being related to the extent of the injury produced by pipette penetration. However, no clear differences could be seen between IN-1 and control Fab-treated cerebella, thus excluding the possibility that the observed structural plastic- ity of Purkinje axons can be attributed to unspecific effects produced by the injected material.

\section{Quantitative analysis of Purkinje axon modifications after application of IN-1 Fab fragment}

Quantitative morphometric analysis of IN-1 Fab fragmentinduced Purkinje axon modifications was performed by reproducing all the calbindin-immunostained axonal profiles in sampled areas of the granular layer (see Material and Methods) from the dorsal (Fig. 5, red) and ventral vermal lobules (Fig. 5, green) at all survival times. On these reproductions (two representative examples are shown in Fig. 5) we analyzed the following parameters: 

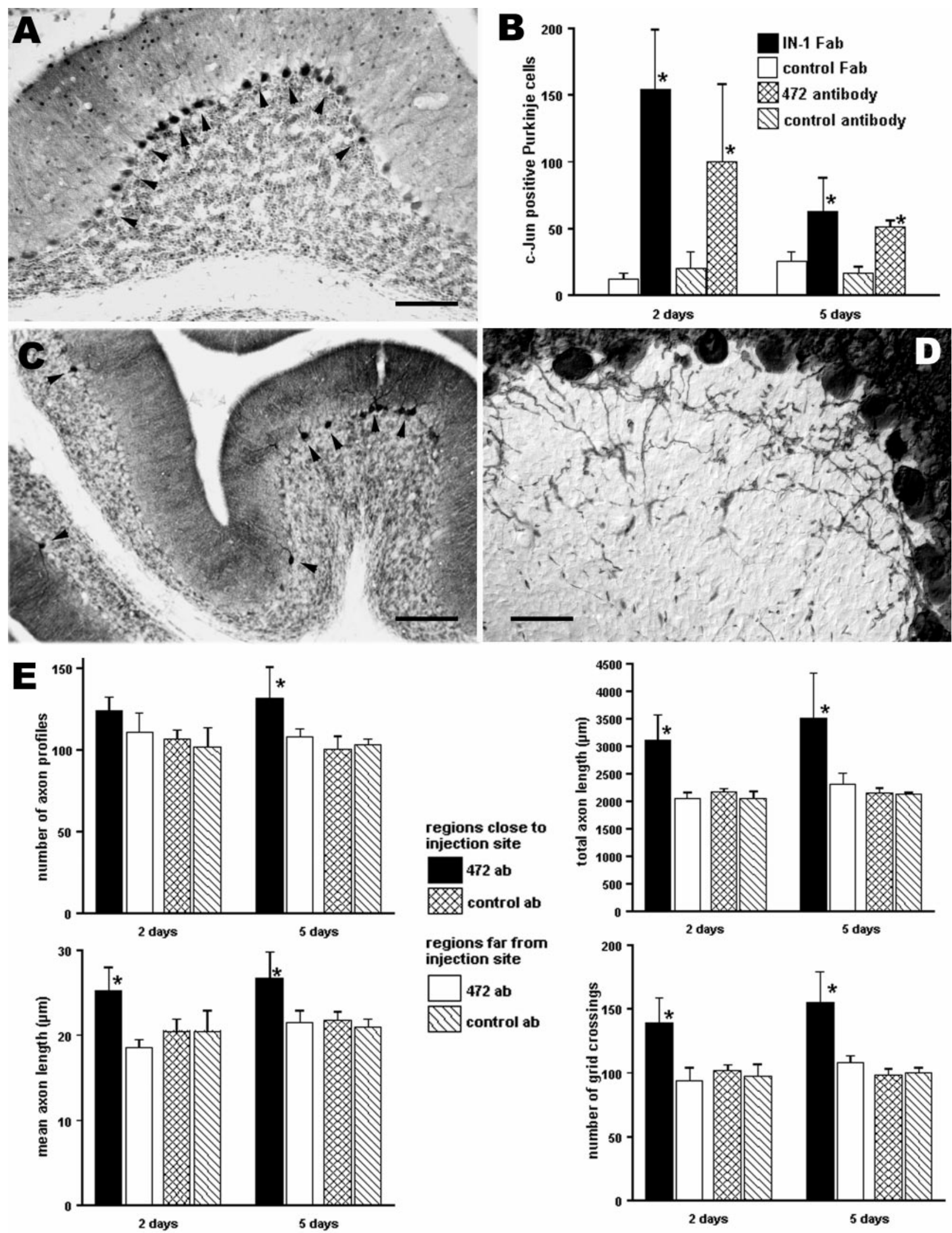

Figure 6. $A-D$, Effects of antiserum 472 application on adult intact Purkinje cells. $A$ shows an anti-c-Jun-labeled section from the dorsal cerebellum $2 \mathrm{~d}$ after antibody injection; arrowheads point to several immunoreactive Purkinje cell nuclei. Quantification of c-Jun-immunolabeled Purkinje cells (B) reveals that the effect of antiserum 472 treatment is milder than that observed in IN-1 Fab fragment-treated rats (Zagrebelsky et al., 1998) but highly different from control antibody-treated rats. Five days after application of the 472 antibody, several Purkinje cells (C, arrowheads) throughout the dorsal vermal cortex become strongly reactive for NADPH diaphorase histochemistry. The sprouting of Purkinje axons is (Figure legend continues) 
number of axon profiles (Fig. $5 A$ ), total axon length (Fig. $5 B$ ), mean axon length (Fig. $5 C$ ), and the number of times the labeled axons crossed a grid superimposed to the drawing (Fig. 5D).

When the values obtained from dorsal and ventral lobules of intact animals were compared, no significant differences were observed for any of the considered parameters (Fig. 5A-D, crosshatched columns), showing that no quantitative differences of Purkinje axon pattern exist between the examined cortical regions of unmanipulated animals. A similar result was obtained by comparing data from dorsal and ventral cerebella treated with control Fab fragment (Fig. 5A-D, hatched columns) (the only statistically significant difference was found for mean axon length at $5 \mathrm{~d}$; Student's $t$ test, $p=0.04$ ). In addition, the values obtained from these animals were not significantly different from those calculated for the relevant cerebellar region in unmanipulated rats (except for total axon length at $7 \mathrm{~d}$; Student's $t$ test, $p=$ 0.028). Thus, control Fab application did not induce any quantitative change in Purkinje axons.

In contrast, when the values obtained from the dorsal cerebellar lobules of IN-1 Fab fragment-treated animals were compared with those from the ventral ones, the internal control, all parameters were increased (Fig. 5A-D, solid columns). The number of axon profiles in the dorsal vermis was significantly increased to $127.7 \%$ at $2 \mathrm{~d}$ (Student's $t$ test, $p=0.006), 140.7 \%$ at $5 \mathrm{~d}$ ( $p=$ $0.011)$, and $139.6 \%$ at $7 \mathrm{~d}(p=0.006)$. The mean axon length was also consistently higher than control, although to a lower extent $(125.8 \%$ at $2 \mathrm{~d} ; 135.2 \%$ at $5 \mathrm{~d} ; 125 \%$ at $7 \mathrm{~d})$. This difference was statistically significant at $2 \mathrm{~d}(p=0.001)$ but not at 5 and $7 \mathrm{~d}$. However, the latter result was conditioned by the variability of this parameter among individual animals, because both comparisons resulted in significant differences when the paired $t$ test was applied ( $p=0.004$ and 0.05 , respectively). The concurrent rise of both the number and length of axon segments led to a large increase in total axon length $(161.2 \%$ at $2 \mathrm{~d}$, Student's $t$ test, $p=$ $0.001 ; 190.2 \%$ at $5 \mathrm{~d}, p=0.008 ; 170.6 \%$ at $7 \mathrm{~d}, p<0.001)$ as well as the number of grid crossings $(159.7 \%$ at $2 \mathrm{~d}, 191 \%$ at $5 \mathrm{~d}$, $170.3 \%$ at $7 \mathrm{~d} ; p<0.001$ for all tests). All of the parameters returned to control levels at $30 \mathrm{~d}$, although some of the values were still significantly different from their internal control (total axon length, $p=0.011$; mean profile length, $p=0.003$; number of grid crossings, $p=0.044$ ).

All of the values obtained from the dorsal vermal lobules of IN-1-treated animals at 2, 5, and $7 \mathrm{~d}$ were significantly higher than those calculated from the same area of intact animals, whereas no significant difference was observed at $30 \mathrm{~d}$. The comparison between the ventral vermis of IN-1-treated and intact rats did not reveal any consistent difference at any survival time. Similarly, all parameters from dorsal cerebellar lobules of IN-1 Fab fragmenttreated animals at 2, 5, and $7 \mathrm{~d}$, but not at $30 \mathrm{~d}$, were significantly different from the relevant values calculated from control Fab fragment-treated rats. Thus, this quantitative analysis fully confirms the conclusion that IN-1 Fab fragment application induces profuse sprouting of Purkinje axons in the same areas in which the expression of injury/growth-associated markers is upregulated.

All parameters were already increased at $2 \mathrm{~d}$, and they were consistently higher at 5 and $7 \mathrm{~d}$. However, statistical comparison of the time course did not show any significant difference between the time points. In contrast, all parameters were significantly different from those obtained at $30 \mathrm{~d}$. Thus, the IN-1 Fab fragment-induced Purkinje axon sprouting develops rapidly after Fab fragment injection, but it is almost completely reversed after 1 month. Both the spatial and temporal evolution of the axon remodeling fairly match those of the cellular changes, although the latter seem to decline more rapidly.

\section{Effects of the application of antiserum 472 against the recombinant $\mathrm{NI}-220$ protein}

To assess the specificity of the effect of the IN-1 Fab fragmentinduced neutralization of the NI-35/250 protein, we performed an additional experimental series in which we injected the affinity-purified antibody 472 raised against a peptide sequence of the recombinant NI-220 protein into the intact cerebellum (Chen et al., 1998; Huber et al., 1998). As a control for these experiments we injected affinity-purified preimmune serum, to which normal rabbit $\mathrm{IgG}$ was added at the same concentration as antibody $472(0.5 \mathrm{mg} / \mathrm{ml})$. These animals were killed 2 or $5 \mathrm{~d}$ after injection.

Injection of antibody 472, but not of control antibody, induced a strong nuclear staining for c-Jun in numerous Purkinje cells distributed over several lobules of the dorsal vermis (Fig. 6A). Such immunostained neurons were also present at $5 \mathrm{~d}$, when many Purkinje cells became reactive for NADPH diaphorase (Fig. 6C). Quantitative analysis of c-Jun-immunolabeled Purkinje cells (Fig. $6 B$ ) revealed significantly higher amounts of reactive neurons in the antibody 472-treated cerebella than in their control counterparts at both survival times (Student's $t$ test, $p=0.036$ at $2 \mathrm{~d}, p<$ 0.001 at $5 \mathrm{~d}$ ). The same result was obtained by comparing IN-1 and control Fab fragment-treated cerebella ( $p<0.001$ at $2 \mathrm{~d}, p=$ 0.03 at $5 \mathrm{~d}$ ). When antibody 472 injections were compared with those from IN-1 Fab fragment applications, the numbers of c-Jun immunolabeled Purkinje cells were somewhat lower, although not significantly different. Also, no statistically significant differences were found between the two control groups.

The application of both 472 and control antibodies did not induce clear alterations in the cerebellum, except for some neuronal loss in the vicinity of the injection site. Microglia activation was similar to that observed after Fab fragment applications, with no overt differences between 472 (Fig. 4C) and control antibody injections (Fig. 4D). In the dorsal vermis of cerebella receiving antibody 472 injections, Purkinje axons did show sprouting, similar to that described for IN-1 Fab fragment treatment (Fig. 6D). Morphometric analysis of Purkinje axons in these cerebella was performed following the same procedure described for Fab fragment injections (Fig. 6E). In the antibody 472-treated cerebella, the values obtained from the dorsal lobules (Fig. 6E, solid columns) were consistently higher and significantly different from those calculated in the ventral lobules (open columns), except for the number of axon profiles at $2 \mathrm{~d}$ (Student's $t$ test, number of profiles, $p=0.128$ at $2 \mathrm{~d}, p=0.045$ at $5 \mathrm{~d}$; total axon length, $p=0.005$ at $2 \mathrm{~d}, p=0.029$ at $5 \mathrm{~d}$; mean axon length, $p=0.003$

\section{$\longleftarrow$}

evident in anti-calbindin-immunostained sections $(D$, at $2 \mathrm{~d}$ survival time). Quantitative analysis of Purkinje axons $(E)$ reveals a consistent increase of all the parameters calculated from dorsal vermal lobules (solid columns) of antibody 472-treated rats compared with those from ventral lobules (open columns). In contrast, no differences exist between dorsal (cross-hatched columns) and ventral (hatched columns) lobules from the cerebella receiving control antibody injections. Asterisks in $B$ and $E$ indicate values that are significantly different from the relevant internal control. Scale bars: $A$, $100 \mu \mathrm{m}$; $C, 200 \mu \mathrm{m} ; D, 50 \mu \mathrm{m}$. 
at $2 \mathrm{~d}, p=0.022$ at $5 \mathrm{~d}$; number of grid crossings, $p=0.007$ at $2 \mathrm{~d}, p=0.008$ at $5 \mathrm{~d}$ ). Comparisons of dorsal and ventral lobules from control antibody-treated animals (Fig. 6E, cross-hatched and hatched columns, respectively) did not yield any statistical difference. Finally, all of the values obtained from dorsal lobules of antibody 472-treated rats were significantly higher than those of the same lobules from control animals (Student's $t$ test, number of profiles, $p=0.015$ at $2 \mathrm{~d}, p=0.03$ at $5 \mathrm{~d}$; total axon length, $p=0.007$ at $2 \mathrm{~d}, p=0.016$ at $5 \mathrm{~d}$; mean axon length, $p=0.02$ at $2 \mathrm{~d}, p=0.023$ at $5 \mathrm{~d}$; number of grid crossings, $p=0.011$ at $2 \mathrm{~d}$, $p=0.003$ at $5 \mathrm{~d}$ ). In contrast, no difference was found when ventral lobules were compared.

On the whole, the effects of antiserum 472 on growthassociated gene expression and axonal sprouting were quantitatively milder than those observed with IN-1 Fab fragment. However, these treatments cannot be compared directly because of the lower protein concentration used with antiserum 472 as compared with IN-1 Fab fragment, and the unknown half-life, tissue penetration, and avidity of the two antibodies. Taken together, these observations show that application of antibody 472 replicates all of the major changes induced by the IN-1 Fab fragment injection and thus strongly support the conclusion that these effects are caused by the neutralization of the NI-35/250 myelinassociated proteins.

\section{DISCUSSION}

To elucidate the physiological function of the NI-35/250 myelinassociated proteins, we have investigated whether functional neutralization of these proteins induces growth phenomena of uninjured axons in the adult intact brain. Our results show the following: (1) a single intraparenchymal application of the neutralizing IN-1 antibody Fab fragment induces a prof use sprouting of Purkinje axons in the granular layer; (2) this axon remodeling parallels the upregulation of growth-associated markers induced by these antibodies in Purkinje cells (Zagrebelsky et al., 1998); (3) both phenomena are reversible, although axon changes outlast the upregulation of cellular markers; (4) the effects of IN-1 Fab fragment application are reproduced by injection of the antibody 472 raised against the recombinant NI-220 protein (Huber et al., 1998). Together with recent reports showing that neutralization of NI-35/250 proteins enhances compensatory sprouting and functional recovery after unilateral corticospinal tract lesions (Thallmair et al., 1998; Z'Graggen et al., 1998), the present observations indicate that these proteins constitutively suppress growth-associated cellular processes in adult central neurons.

\section{Calbindin-immunostained profiles are Purkinje axons}

Purkinje axons were visualized by immunolabeling for calbindin that, within the cerebellum, yields a selective Golgi-like stain of all Purkinje cells. Several considerations exclude the possibility that the increased number of neurites observed in the granular layer of the lobules around the injection site might be attributed to a more efficient penetration of anti-calbindin antibodies into the cortical regions affected by Fab-fragment injections. The morphology and course of the axon profiles as well as their distribution throughout the whole depth of the granular layer are definitively different from all previous descriptions of Purkinje axons labeled by Golgi stain (Ramón y Cajal, 1911; Chan-Palay, 1971) or intracellular tracer injections (Crepel et al., 1980; Bishop, 1982). Indeed, the only report describing axon collaterals ending in this layer (Chan-Palay, 1971) refers to neurons from ventral lobule IX, where we also observed a thick Purkinje axon terminal network. In addition, the possibility that these profiles belong to other neurons induced to express calbindin by the Fab fragment treatment is also very unlikely. (1) No cell bodies or dendrites other than Purkinje cells were labeled in the treated cerebella; (2) the morphology and distribution of labeled axon profiles did not correspond to any of the known cerebellar afferent systems, and (3) in many instances they originated directly from Purkinje axons. Thus, the labeled profiles in the granular layer actually represent newly formed processes sprouting from Purkinje axons.

\section{Regulatory mechanisms of Purkinje axon sprouting}

Among CNS neurons, adult Purkinje cells are most peculiar for their poor regenerative capabilities (Rossi et al., 1995a; Bravin et al., 1997; Dusart et al., 1997), which are paralleled by an extremely weak cellular response to axotomy (Zagrebelsky et al., 1998). Despite the failure of Purkinje axons to regenerate into growth-permissive territories, they spontaneously sprout starting from 3 months after axotomy (Dusart and Sotelo, 1994), and this phenomenon has been related to the appearance of growthpermissive molecules in their microenvironment (Dusart et al., 1999). A similar sprouting develops within a few days after axotomy in GAP-43-overexpressing Purkinje cells (Buffo et al., 1997). Taken together, these observations indicate that intrinsic neurite growth capabilities of Purkinje cells are under the control of environmental cues that either restrain constitutively active plastic properties or suppress the expression of growth-associated genes. The present results further support this conclusion by showing that sprouting of intact Purkinje axons can be induced by removing a constitutive inhibitory action exerted by myelinassociated neurite growth inhibitory proteins.

When Purkinje cells are axotomized the sprouting appears later, is long-lasting, and expands over time (Dusart and Sotelo, 1994; Buffo et al., 1997; Dusart et al., 1999). The outgrowing processes form heterotopic synapses in the granular layer (Dusart et al., 1999). In contrast, the outgrowth observed in our experiments occurs quickly and is transitory, and the paucity of boutons present on the newly formed processes suggests that if new contacts are formed they are very few. The rather fast reversal of the IN-1 Fab fragment-induced cellular changes and axon plasticity is likely a result of the fact that single antibody injections lead to a transient neutralization of NI-35/250 proteins. As the antibody activity fades out, myelin-associated proteins recover their function and Purkinje cell modifications regress. Another important difference to postaxotomy sprouting, which likely affects the elongation and maintenance of new processes, is the availability of free postsynaptic sites left vacant by degenerated extracerebellar afferents (Dusart et al., 1999). Interestingly, a vigorous Purkinje axon sprouting with the formation of heterotopic synapses occurs in organotypic cerebellar cultures after ablation of granule cells and glia (Blank et al., 1982). These phenomena are reversed when these cell populations are reintroduced into the culture (Seil, 1996), indicating that the availability of postsynaptic sites is crucial for the maintenance of Purkinje axon branches. Free postsynaptic sites are most likely very rare in the uninjured Fab fragment-treated cerebella. It is thus possible that the Purkinje axon sprouts gradually retract because they are not sustained by target support, as shown for the terminal branches of adult target-deprived axons (Rossi et al., 1993, 1995b; Marty et al., 1994).

Purkinje axon changes occurring after IN-1 Fab fragment application are spatially and temporally related to the upregula- 
tion of injury/growth-associated markers. Nevertheless, axon growth processes develop very rapidly and also outlast the duration of cell body modifications. The precise mechanism of action of the neutralizing antibodies remains to be established. Assuming that NI-35/250 proteins are expressed on oligodendrocyte surface and their activity is contact-mediated, as shown in vitro (Bandtlow et al., 1990), changes in neuronal gene expression might require that antibodies penetrate into the space between axon and myelin to disrupt established ligand-receptor interactions. Alternatively, however, in the case of axon sprouting, even more distantly located inhibitory molecules distributed in the axon microenvironment may induce the collapse of spontaneously outgrowing processes. Indeed, the fast onset of axon plasticity suggests that it might be initially triggered by the removal of local inhibition on preexisting axon growth properties that do not require the transcription of new genes. It is thus likely that NI-35/250 protein neutralization removes inhibitory control on a dual mechanism involving a constitutively active growth machinery, which is subsequently sustained by the upregulation of specific growth-associated genes. On the other hand, the longer duration of axon plasticity in comparison to cellular changes suggests that the withdrawal of newly formed processes is not solely attributable to the recovery of NI-35/250 inhibitory function, but rather to the lack of supporting environmental cues. Finally, it is noteworthy that Purkinje axon sprouting was restricted to the granular layer, whereas no morphological modifications could be detected in the underlying white matter. Although this might reflect distinct growth properties in the different axon compartments, it is also possible that the Fab fragment penetration and activity were less efficient in the white matter, where tissue architecture is more compact and higher amounts of myelin are present.

\section{Role of NI-35/250 proteins in the control of terminal arbor plasticity}

Although NI-35/250 proteins are constitutively expressed in the adult CNS, major attention has been paid to their inhibitory activity on the regeneration of severed central axons (Schwab et al., 1993; Schwab and Bartholdi, 1996), and their physiological function in the intact CNS remains unclear. Functional blockade of these proteins during development indicates that they prevent maturing axons from growing or sprouting out of their proper pathways and thus from forming aberrant connections (Schwab and Schnell, 1991; Colello and Schwab, 1994; Kapfhammer and Schwab, 1994a,b). Accordingly, in the adult these myelinassociated proteins would restrict plasticity to defined CNS areas and arrest axon sprouting at unwanted sites, thus contributing to the maintenance of connection specificity. Indeed, our results show that neutralization of these proteins induces the aberrant growth of Purkinje axon branches into portions of the granular layer where they are normally absent. Nevertheless, several examples of postlesion reinnervation phenomena show that highly specific connection patterns can be restored in the adult CNS (Zagrebelsky et al., 1996; Frotscher et al., 1997; Strata et al., 1998) and even in the presence of IN-1 antibodies (Thallmair et al., 1998; Z'Graggen et al., 1998). In all of these cases, however, axonal plasticity occurs in response to injury, which may modify the reciprocal interactions between neurons. For instance, it has been shown that positional information for retinal axons is reexpressed in the adult mammalian superior colliculus only after denervation (Wizenmann et al., 1993), and IN-1 antibodies do not interfere with axon-target recognition in this model (Bähr and Schwab, 1996). It is thus likely that the inhibitory action of the NI-35/250 proteins on axon sprouting is especially important in the intact adult brain, in which specific recognition cues required to form appropriate connections are downregulated. This suggests that these proteins may contribute to restrict terminal arbor plasticity within defined portions of gray matter areas, such as the upper granular layer for Purkinje cell axons, specific layers of the superior colliculus for retinal axons (Kapfhammer et al., 1992), or appropriate laminae of the dorsal horn for sensory axons (Schwegler et al., 1995). In this way, the plastic properties of distinct axon populations terminating within the same gray matter area can be differentially regulated to allow adaptive structural modifications while preserving the proper targeting and compartmentation of the different inputs.

\section{REFERENCES}

Bähr M, Schwab ME (1996) Antibody that neutralizes myelin-associated inhibitors of axon growth does not interfere with recognition of targetspecific guidance information by retinal axons. J Neurobiol 30:281-292.

Bandtlow C, Zachleder T, Schwab ME (1990) Oligodendrocytes arrest neurite growth by contact inhibition. J Neurosci 10:3837-3848.

Bandtlow C, Schiweck W, Tai HH, Schwab ME, Skerra A (1996) The Escherichia coli-derived Fab fragment of the IgM/kappa antibody IN-1 recognizes and neutralizes myelin-associated inhibitors of neurite growth. Eur J Biochem 241:468-475.

Bishop GA (1982) The pattern of distribution of the local axonal collaterals of Purkinje cells in the intermediate cortex of the anterior lobe and paramedian lobule of the cat cerebellum. J Comp Neurol 210:1-9.

Blank NK, Seil FJ, Herndon RM (1982) An ultrastructural study of cortical remodelling in cytosine arabinoside induced granuloprival cerebellum in tissue culture. Neuroscience 7:1509-1531.

Bravin M, Savio T, Strata P, Rossi F (1997) Olivocerebellar axon regeneration and target reinnervation following dissociated Schwann cell grafts in surgically injured cerebella of adult rats. Eur J Neurosci 9:2634-2649.

Buffo A, Holtmaat AJDG, Savio T, Verbeek S, Oberdick J, Oestreicher AB, Gispen WH, Verhaagen J, Rossi F, Strata P (1997) Targeted overexpression of the neurite growth-associated protein B-50/GAP-43 in cerebellar Purkinje cells induces sprouting in response to axotomy, but does not allow axon regeneration into growth permissive transplants. J Neurosci 17:8778-8791.

Buffo A, Zagrebelsky M, Skerra A, Schwab ME, Strata P, Rossi F (1999) Application of IN-1 antibodies to the adult rat cerebellum induces the outgrowth of intact Purkinje cell axons. Soc Neurosci Abstr 25:1000.

Caroni P, Schwab ME (1988) Antibody against myelin-associated inhibitor of neurite growth neutralizes non-permissive substrate properties of CNS white matter. Neuron 1:85-96.

Caroni P, Schwab ME (1989) Codistribution of neurite growth inhibitors and oligodendrocytes in rat CNS: appearance follows nerve fiber growth and precedes myelination. Dev Biol 136:287-295.

Chan-Palay V (1971) The recurrent collaterals of Purkinje cell axons: a correlated study of the rat cerebellar cortex with electron microscopy and the Golgi method. Z Anat Entwicklungsgesch 134:200-234.

Chen DF, Jhaveri S, Schneider GE (1995) Intrinsic changes in developing retinal neurons result in regenerative failure of their axons. Proc Natl Acad Sci USA 92:7287-7291.

Chen MS, Huber AB, van der Haar ME, Frank M, Spilmann AA, Christ F, Schwab ME (1998) Neurite outgrowth inhibitory factors in CNS myelin: molecular characterization of Nogo (NI-35/250). Soc Neurosci Abstr 24:1766.

Colello RJ, Schwab ME (1994) A role for oligodendrocytes in the stabilization of optic axon numbers. J Neurosci 14:6446-6452.

Crepel F, Delhaye-Bouchaud N, Dupont JL, Sotelo C (1980) Dendritic and axonic fields of Purkinje cells in developing and $\mathrm{X}$-irradiated rat cerebellum. A comparative study using intracellular staining with horseradish peroxidase. Neuroscience 5:333-347.

De Camilli P, Miller PE, Levitt P, Walter U, Greengard P (1984) Anatomy of the cerebellar Purkinje cells in the rat determined by a specific immunohistochemical marker. Neuroscience 11:761-817.

Dusart I, Sotelo C (1994) Lack of Purkinje cell loss in adult rat cerebellum following protracted axotomy: degenerative changes and reactive attempts of the severed axons. J Comp Neurol 347:211-232. 
Dusart I, Airaksinen MS, Sotelo C (1997) Purkinje cell survival and axonal regeneration are age dependent: an in vitro study. J Neurosci 17:3710-3726.

Dusart I, Morel MP, Wehrlé R, Sotelo C (1999) Late axonal sprouting of injured Purkinje cells and its temporal correlation with permissive changes in the glial scar. J Comp Neurol 408:399-418.

Eccles JC, Ito M, Szentágothái J (1967) The cerebellum as a neuronal machine. New York: Springer.

Frotscher M, Heimrich B, Deller T (1997) Sprouting in the hippocampus is layer specific. Trends Neurosci 20:218-223.

Holm K, Isacson O (1999) Factors intrinsic to the neuron can induce and maintain its ability to promote axonal outgrowth: a role for BCL2? Trends Neurosci 22:269-273.

Huber AB, Chen MS, van der Haar ME, Schwab ME (1998) Developmental expression pattern and functional analysis of Nogo (formerly NI-35/250), a major inhibitor of CNS regeneration. Soc Neurosci Abstr 24:1559.

Kapfhammer JP, Schwab ME (1994a) Inverse patterns of myelination and GAP-43 expression in the adult CNS: neurite growth inhibitors as regulators of neuronal plasticity? J Comp Neurol 340:194-206.

Kapfhammer JP, Schwab ME (1994b) Increased expression of growthassociated protein GAP-43 in myelin-free rat spinal cord. Eur J Neurosci 6:403-411.

Kapfhammer JP, Schwab ME, Schneider GE (1992) Antibody neutralization of neurite growth inhibitors from oligodendrocytes results in expanded pattern of postnatally sprouting retinocollicular axons. J Neurosci 12:2112-2119.

Marty S, Weinitz JM, Peschanski M (1994) Target dependence of adult neurons: pattern of terminal arborizations. J Neurosci 14:5257-5266.

McKerracher L, David S, Jackson DL, Kottis V, Dunn RJ, Braun PE (1994) Identification of myelin-associated glycoprotein as a major myelin-derived inhibitor of neurite growth. Neuron 13:805-811.

Mukhopadhyay G, Doherty P, Walsh FS, Crocker PR, Filbin MT (1994) A novel role of myelin-associated glycoprotein as an inhibitor of axonal regeneration. Neuron 13:1-20.

Mugnaini E (1972) The histology and cytology of the cerebellar cortex. In: The comparative anatomy and histology of the cerebellum: the human cerebellum, cerebellar connections and cerebellar cortex (Larsell O, Jansen J, eds), pp 201-265. Minneapolis: University of Minnesota.

Müller CM, Gardziella S, Schwab ME (1994) Role of the myelinassociated neurite growth inhibitor NI35/250 in the determination of critical period plasticity in kitten visual cortex. Soc Neurosci Abstr 20:1471.

Palay SL, Chan-Palay V (1974) Cerebellar cortex. Cytology and organization. New York: Springer.

Ramón y Cajal S (1911) Histologie du système nerveux de l'homme et des vertébrés. Paris: Maloine.

Ramón y Cajal S (1928) Degeneration and regeneration of the nervous system. Reprint (May R, translator). Oxford: Oxford UP, 1991.

Rossi F, Borsello T, Vaudano E, Strata P (1993) Regressive modifications of climbing fibres following Purkinje cell degeneration in the cerebellar cortex of the adult rat. Neuroscience 53:759-778.

Rossi F, Borsello T, Strata P (1994a) Embryonic Purkinje cells grafted on the surface of the adult uninjured rat cerebellum migrate in the parenchyma and induce sprouting of intact climbing fibres. Eur J Neurosci 6:121-136.
Rossi F, Borsello T, Strata P (1994b) Exposure to kainic acid mimics the effects of axotomy in cerebellar Purkinje cells of the adult rat. Eur J Neurosci 6:392-402.

Rossi F, Jankovski A, Sotelo C (1995a) Differential regenerative response of Purkinje cell and inferior olivary axons confronted with embryonic cerebellar grafts: environmental cues versus intrinsic neuronal determinants. J Comp Neurol 359:663-677.

Rossi F, Jankovski A, Sotelo C (1995b) Target neuron controls the integrity of afferent axon phenotype: a study on the Purkinje cellclimbing fiber system in cerebellar mutant mice. J Neurosci 15:2040-2056.

Schwab ME, Bartholdi D (1996) Degeneration and regeneration of axons in the lesioned spinal cord. Physiol Rev 76:319-370.

Schwab ME, Schnell L (1991) Channeling of developing corticospinal tract axons by myelin-associated neurite growth inhibitors. J Neurosci 11:709-721.

Schwab ME, Kapf hammer JP, Bandtlow CE (1993) Inhibitors of neurite growth. Annu Rev Neurosci 16:565-595.

Schwegler G, Schwab ME, Kapf hammer JP (1995) Increased collateral sprouting of primary afferents in myelin-free spinal cord. J Neurosci 15:2756-2767.

Seil FJ (1996) Neural plasticity in cerebellar cultures. Prog Neurobiol 50:533-556.

Skene JHP (1989) Axonal growth-associated proteins. Annu Rev Neurosci 12:127-156.

Skene JHP (1992) Retrograde pathways controlling expression of major growth cone components in the adult CNS. In: The nerve growth cone (Letourneau PC, Kater SB, Macagno ER, eds), pp 463-475. New York: Raven.

Strata P, Zagrebelsky M, Bravin M, Rossi F (1998) Map projection rewiring in the adult cerebellum after lesion. In: Neuronal circuits and networks, Vol 167 (Nicholls J, Torre V, eds), pp 169-185. NATO/ASI series, Series F: Computer and Systems Sciences. Berlin: Springer.

Thallmair M, Metz GAS, Z'Graggen WJ, Raineteau O, Kartje GL, Schwab ME (1998) Neurite growth inhibitors restrict plasticity and functional recovery following corticospinal tract lesions. Nat Neurosci 1:124-131.

Vanek P, Thallmair M, Schwab ME, Kapfhammer JP (1998) Increased lesion-induced sprouting of corticospinal fibres in the myelin-free spinal cord. Eur J Neurosci 10:45-56.

Wizenmann A, Thies E, Klostermann S, Bonhoeffer F, Bähr M (1993) Appearance of target-specific guidance information for regenerating axons after CNS lesions. Neuron 11:975-983.

Zagrebelsky M, Rossi F, Hawkes R, Strata P (1996) Topographically arranged climbing fibre sprouting in the adult rat cerebellum. Eur J Neurosci 8:1051-1054.

Zagrebelsky M, Buffo A, Skerra A, Schwab ME, Strata P, Rossi F (1998) Retrograde regulation of growth-associated gene expression in adult rat Purkinje cells by myelin-associated neurite growth inhibitory proteins. J Neurosci 18:7912-7929.

Z'Graggen WJ, Metz GAS, Kartje GL, Thallmair M, Schwab ME (1998) Functional recovery and enhanced corticofugal plasticity after unilateral pyramidal tract lesion and blockade of myelin-associated neurite growth inhibitors in adult rats. J Neurosci 18:4744-4757. 